This item was submitted to Loughborough's Research Repository by the author.

Items in Figshare are protected by copyright, with all rights reserved, unless otherwise indicated.

\title{
Overmoulding of electronics for end of life recovery
}

PLEASE CITE THE PUBLISHED VERSION

PUBLISHER

(C) IEEE

VERSION

VoR (Version of Record)

LICENCE

CC BY-NC-ND 4.0

REPOSITORY RECORD

Hutt, David A., Nee-Joo Teh, Farhad Sarvar, David C. Whalley, Paul J. Palmer, Paul Anderson, Balasubramanian Kandasubramanian, Peter Morris, Stephen Prosser, and Phillip O'Brien. 2019. "Overmoulding of Electronics for End of Life Recovery". figshare. https://hdl.handle.net/2134/4187. 
This item was submitted to Loughborough's Institutional Repository (https://dspace.lboro.ac.uk/) by the author and is made available under the following Creative Commons Licence conditions.

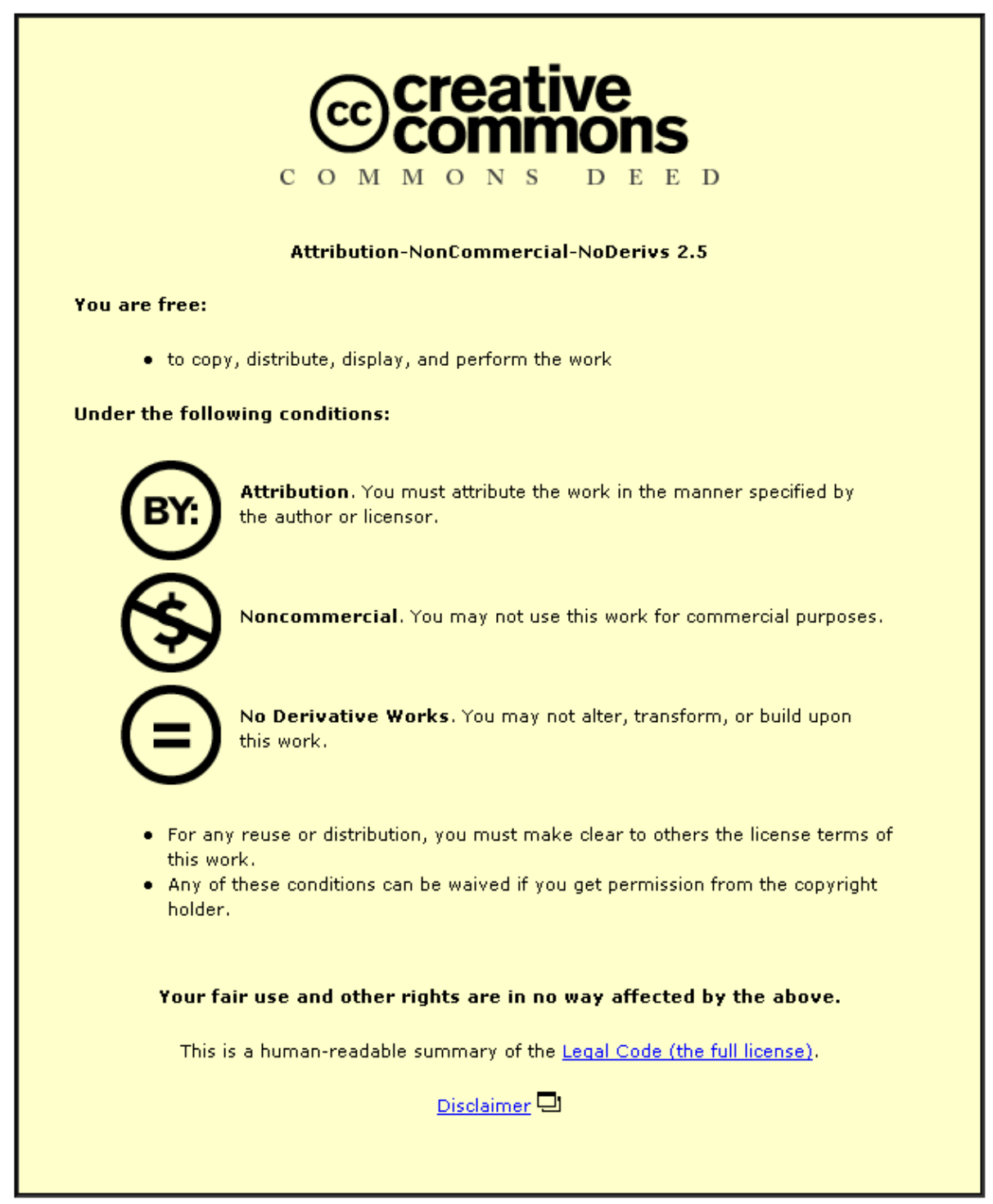

For the full text of this licence, please go to: http://creativecommons.org/licenses/by-nc-nd/2.5/ 


\section{Overmoulding of Electronics for End of Life Recovery}

David A. Hutt ${ }^{1}$, Nee Joo Teh ${ }^{1}$, Farhad Sarvar ${ }^{1}$, David C. Whalley ${ }^{1}$, Paul J. Palmer ${ }^{1}$, Paul Anderson $^{2}$, Bala Kandasubramanian ${ }^{2}$, Peter Morris ${ }^{3}$, Stephen Prosser ${ }^{4}$, Philip O'Brien ${ }^{5}$

${ }^{1}$ Wolfson School of Mechanical and Manufacturing Engineering, Loughborough University, Loughborough, LE 11 3TU, UK

${ }^{2}$ Pera Technology, Pera Innovation Park, Melton Mowbray, Leicestershire, LE13 0PB, UK

${ }^{3}$ PVAXX Research and Development Ltd, Kemble Business Park, Malmesbury, Wiltshire, SN16 9SH, UK

${ }^{4}$ TRW Automotive Ltd, Stratford Road, Solihull, West Midlands, B90 4GW, UK

${ }^{5}$ Rosti Ltd, 29/33 Holmethorpe Avenue, Redhill, Surrey, RH1 2NQ, UK

\begin{abstract}
With the increasing use of electronic control systems in automotive applications, the environments in which they are required to operate are becoming evermore demanding. For improved functionality and to reduce the number of interconnections it is desirable to place the electronic control units (ECUs) as close as possible to the sensors and actuators they interact with, and they can increasingly be found mounted on engine, transmission and chassis components. The electronics are therefore exposed to high/low temperatures, high humidity, vibration and corrosive fluids. In order to protect the electronics and maintain reliability in safety critical areas, great lengths are taken to mount the devices in ways that will prevent the ingress of moisture, cushion shocks and dissipate heat. Potting of electrical devices with thermosetting polymers has been a commonplace method to install a protective layer over the circuit assemblies, which are often mounted in separate boxes within the vehicle. However, with the drive to reduce vehicle weight and increase recyclability, there has been much interest in the use of overmoulding with thermoplastic polymers, not only to provide protection, but to enable the electronics to be mounted into a structural component of the vehicle thereby saving space and weight and eliminating a level of packaging. While this has been shown to be a practical way forward in terms of reliability, the recyclability of the thermoplastic polymer is compromised by the intermixed electronics that are hard to separate economically. The increasing legislative demands to recycle as much of the vehicle as possible at the end of life means that methods for the efficient separation of the electronics from the overmoulding polymer must be developed to enable the production of clean, high value, recyclate streams. Without these separation techniques, the widespread uptake of the overmoulding technology will not be attractive to manufacturers.
\end{abstract}

This paper reports on a project investigating the recyclable overmoulding of electronic components for use in automotive applications. A two-shot process has been used to encapsulate the components. A water soluble polymer is first used to overmould the printed circuit board, which is subsequently incorporated into a second overmould of engineering thermoplastic. The engineering thermoplastic not only protects the water soluble polymer from the environment, but can be used to form a structural component of the vehicle, for example a motor housing. To separate the electronics from the polymer at the end of life it is necessary to expose the water soluble material, that can then be dissolved away allowing the electronics to be removed from the engineering thermoplastic that comprises the bulk of the assembly. This process allows both the water soluble and engineering polymer to be easily recycled as they will not be contaminated with metallic materials.

Due to the high viscosity of thermoplastic polymer melts, injection moulding involves much higher pressures than potting or transfer moulding of thermosetting materials. As part of this work, studies have been carried out to develop methods to overmould the circuit boards without distortion or damage to the electronics due to these high pressures. Test assemblies have subsequently undergone accelerated testing to investigate their reliability when exposed to harsh environments typical of automotive applications. To enable easy separation of the electronics from the polymer at end of life, techniques have been established to easily expose the inner layer of water soluble polymer so that it can subsequently be dissolved allowing the electronics to be removed. Finally, thermal modelling has been used to understand how the polymer layers will affect the dissipation of heat from the electronic components and therefore how they may limit the achievable operational power levels in overmoulded modules. 